\title{
Automation as a Driver of Digital Transformation in Local Government
}

\author{
Exploring Stakeholder Views on an Automation Initiative in a Swedish Municipality
}

\author{
Ida Lindgren \\ Department of Management and \\ Engineering, Linköping University \\ ida.lindgren@liu.se
}

\author{
Daniel Toll \\ Department of Management and \\ Engineering, Linköping University \\ daniel.toll@liu.se
}

\author{
Ulf Melin \\ Department of Management and \\ Engineering, Linköping University \\ ulf.melin@liu.se
}

\begin{abstract}
Local government organizations in Sweden are under pressure from policy makers and leading politicians to accelerate digital transformation of administrative tasks, in order to make public service provision more efficient and effective. As part of this digital transformation, local governments are currently investigating and implementing digital technologies that can execute administrative tasks automatically, without involvement of administrative staff. We explore an automation initiative in a Swedish municipality using a qualitative case study. Our analysis is conducted from a stakeholder perspective, investigating (1) how different stakeholders interpret automation as part of the municipality's ongoing digitalization, and (2) their views on expected outcomes of automation of administrative tasks. Our analysis shows that different stakeholder groups hold different definitions of what digitalization and automation means for their organization, and what outcomes can be expected of automation of administrative tasks in their organization. The analysis further shows that national policy documents encourage local governments to use a specific technical solutions for automation (robotic process automation); however, this technology is viewed as somewhat problematic by the stakeholders working with IT in the organization. Our analysis contributes with an illustration of challenges that municipalities face in their endeavor to find ways of developing automation of administrative tasks, and call for further research on this topic.
\end{abstract}

\section{CCS CONCEPTS}

- Social and professional topics; $\bullet$ Professional topics; $\bullet$ Management of computing and information systems;

\section{KEYWORDS}

automation, public sector, digitalization, stakeholders, local government

\section{ACM Reference Format:}

Ida Lindgren, Daniel Toll, and Ulf Melin. 2021. Automation as a Driver of Digital Transformation in Local Government: Exploring Stakeholder

Permission to make digital or hard copies of all or part of this work for personal or classroom use is granted without fee provided that copies are not made or distributed for profit or commercial advantage and that copies bear this notice and the full citation on the first page. Copyrights for components of this work owned by others than ACM must be honored. Abstracting with credit is permitted. To copy otherwise, or republish, to post on servers or to redistribute to lists, requires prior specific permission and/or a fee. Request permissions from permissions@acm.org.

DG.O'21, fune 09-11, 2021, Omaha, NE, USA

(C) 2021 Association for Computing Machinery.

ACM ISBN 978-1-4503-8492-6/21/06 ..\$15.00

https://doi.org/10.1145/3463677.3463685
Views on an Automation Initiative in a Swedish Municipality. In DG.O2021: The 22nd Annual International Conference on Digital Government Research (DG.O'21), June 09-11, 2021, Omaha, NE, USA. ACM, New York, NY, USA, 10 pages. https://doi.org/10.1145/3463677.3463685

\section{INTRODUCTION}

This paper explores automation as a driver of digital transformation by studying an automation initiative in a Swedish municipality. In the latest UN e-government survey (United Nations, 2020), Sweden was ranked as one of the leading countries in e-government development worldwide (rank 6). Similarly, the annual e-government benchmark report, authorized by the European Commission (European Commission, 2020, p.111), illustrates how Sweden is ranked amongst the ten countries with "fruitful e-government", referring to countries that combine "a solid supply of digital services with a high number of users". In spite of comparative rankings still being high, Sweden's position has dropped over time. As a response to this change in rank and to demographic and fiscal changes, politicians and policy makers seek to further accelerate digital transformation in government organizations on all governmental levels; particularly in local government organizations. In order to achieve the said acceleration, automation of administrative tasks is promoted as a next step in digitalizing public service provision in local government.

Digital services have long been encouraged by policy makers and researchers as the main interface for information exchange between citizens and local government organizations, enabling self-service for citizens as well as improving data quality for local governments. Automation of internal administrative tasks, part of public service provision, is now outlined as a continuation of the development towards a more digital local government. A strong promotor of automation of administrative processes in Sweden is the Swedish Association for Local Government and Regions (SALAR). SALAR's encouragement to automate tasks in local government must be understood against the background that most Swedish local government organizations are struggling with decreasing budgets and recruitment difficulties. The quality of local governments' service provision is likely to decrease if measures are not taken to lower costs and increase efficiency; here, automation is seen as a way to eliminate administrative tasks and therethrough save money and/or redistribute resources within the organization (SALAR(a), 2018; SALAR(b), 2018; SOU, 2016; SOU, 2014). However, SALAR does not provide details or recommendations on how to operationalize automation in practice. As a part of the Swedish governance model, local government organizations are independent (from each 
other and in relation to the national government level), and can make their own decisions on e.g. what technical solutions to invest in. Simultaneously, they are under pressure from more "soft" governance initiatives, like success stories, national ambitions, and visions formulated by leading politicians and digital champions on a national level. As a result, employees in local government organizations need to interpret and pursue digitalization and automation as they see fit; how automation in local government is understood and developed, and by whom, is yet underexplored and constitutes a research gap.

Automation is here understood as "the execution by a machine agent (usually a computer) of a function that was previously carried out by a human" (Parasuraman and Riley, 1997, p.231). As is the case for digitalization in general, automation denotes a change from one state to another; hence, automation is not a fixed object and what is considered automation will change with time. This is captured by (Parasuraman and Riley, 1997, p.231); "[w]hen the reallocation of a function from human to machine is complete and permanent, then the function will tend to be seen simply as a machine operation, not as automation". This means that most of the machine operations present in local government today were once handled manually and through the implementation of various digital technologies, these operations were at some point in time automated (however, these machine operations are not considered as automation anymore). As such, automation is not a new phenomenon in local government; so why has automation gained renewed attention now? Part of the answer lies in cheaper and more available technologies for automation of administrative tasks, such as Robotic Process Automation (RPA). Better and more affordable AI-solutions (e.g., machine learning, algorithmic decision making, pattern recognition) also play a role in directing the limelight towards automation as a promising way for enabling more efficient and effective ways of working. Furthermore, scholars highlight that the scope of what can now be automated has widened (Wajcman, 2017); tasks that have previously been considered as 'cognitive', thus in need of human involvement or discretion (cf. Lipsky, 2010), can now be performed, at least in theory, by machines. Not much is yet known about how automation by these kinds of technology affects operations in local government. This means that automation in this particular context requires closer attention.

Based on previous experiences of digitalization in the public sector, there is reason to be cautious and raise questions when a particular set of technologies is pinpointed as a way of resolving complex (and to some extent inherent) issues related to administrative tasks in public sector organizations. The literature on digital government can present many examples of initiatives being steered by techno-optimism (Hood and Dixon, 2015), leading to unexpected and unwanted consequences for those working in government (Margetts and Hood, 2012). There is, for example, little empirical evidence for the claim that digitalization will save money for local government; rather, digitalization changes and redistributes the costs within the organization (cf. Hood and Dixon, 2015). In addition, a consistent problem for digital transformation in the public sector concerns the difficulties in mapping and understanding how various stakeholders will affect and be affected by the changes made in technology and organizational setups (Axelsson et al., 2013; Rose et al., 2018). Seen from a stakeholder perspective, automation of administrative tasks is a good example of an organizational change that is (a) stimulated by one set of stakeholders (e.g., policy makers), (b) managed and implemented by other sets of stakeholders (e.g., IT-professions and managers), and then finally, (c) affecting yet other sets of stakeholders (e.g., administrative staff, case workers, citizens). The stakeholder perspective is further motivated by previous studies that illustrate how respecting stakeholders' interests can lead to improved e-government projects, as an ethical response to stakeholders' interests can make a public organization reliable and trustworthy, thereby increasing its political credibility (Flak and Rose, 2005). To current date, there are only a few studies that have explored the use and consequences of automation of administrative tasks in the Swedish public sector context (Wihlborg et al., 2016; Ranerup and Henriksen, 2019; Ranerup and Henriksen, 2020), and a clear stakeholder perspective is missing in those studies. Hence, there is a knowledge gap concerning stakeholder influence and how various stakeholders in local government are affected by automation of administrative tasks.

Against this background, the aim of this paper is two-fold; to investigate and map (1) how different stakeholders interpret automation as part of the municipality's ongoing digitalization, and (2) their views on expected outcomes of automation of administrative tasks. Swedish municipalities, as an example of local government, make interesting cases for investigating uptake of automation technologies and use due to their relatively slow uptake of e-government (in comparison to government organizations on the state and agency level). Although digital transformation has been on the municipalities' agendas for close to two decades, most of these organizations are still far from reaching the goals set in local and national digital agendas. There are exceptions, but the municipalities' digital transformation has generally been slow and hampered by technological, organizational and legal obstacles (Goldkuhl et al., 2014). These challenges are experienced by local governments also outside of Sweden (Tangi et al., 2021); the results should therefore be relevant also outside the Swedish context.

\section{AUTOMATION IN LOCAL GOVERNMENT}

In a set of policy documents (SALAR(b), 2018; SOU, 2014; SOU, 2016), Swedish municipalities are encouraged to automate their case handling processes, i.e., administrative tasks. In this setting, case handling is understood as an activity in which "[...] information is collected, managed, assessed, and communicated” (SALAR(a), 2018b, p.5; our translation). In general, administrative work at Swedish municipalities is supported by IT-systems of various kinds and complexity; typically a mix of standardized and locally developed systems. However, the systems in use are often old, non-flexible, and therefore difficult to integrate with one another. As a consequence, human case workers often work as system integrators by copying and inserting data from one system to another. This type of administrative task is time consuming, often perceived as boring, and is associated with a number of risks for errors in the handling of data (SOU, 2014). Swedish municipalities report that there is an increasing demand for systems development and integration, but that - at the same time - it is too costly to invest in new enterprise systems that could enable the use of API and other forms of 
Table 1: Stakeholder roles in e-government projects (based on Heeks, 2006).

\begin{tabular}{ll}
\hline Stakeholder role & Description \\
\hline $\begin{array}{l}\text { Project manager/team } \\
\text { Supplier(s) }\end{array}$ & Those who will analyze, design, and build the e-government system. \\
Operators & Those who will supply the technology and other resources required by the e-government system. \\
Clients & Those who will be carrying out the activities/processes that make the e-government system work. \\
& Primary clients are on the immediate receiving end of what the e-government system does or outputs. \\
& Sometimes these will be outside the government (e.g. citizens or businesses). Sometimes, though, these \\
& will be inside government (i.e. public servants): in this case, there may also be secondary clients who will \\
be affected indirectly by the system since they are served by the primary clients (e.g. citizens served by & \\
those public servants). & The person (or group) who drives the project on and seeks to justify its implementation. \\
Thampion(s) & The person (or group) who pays for the expense and effort required to develop the new e-government \\
sponsor(s) & The manager of the organization or department that will own and use the system, who is ultimately \\
Owner & responsible for the system. \\
Other stakeholders & Such as politicians and influencers.
\end{tabular}

system integration (SALAR(a), 2018). As a response, a form of lightweight (Penttinen et al., 2018) and cheaper digital solution has been identified as an alternative to traditional methods; Robotic Process Automation (RPA). IT consultants, policy makers and researchers refer to RPA and automation of administrative tasks as a way to increase efficiency in local government (e.g., SOU, 2014; SOU, 2016; Willcocks and Lacity, 2016). Letting RPA solutions handle information and prepare decisions in public service provision processes is likely to bring various (and different) consequences for a multitude of stakeholders, in particular for employees that are currently performing the actions replaced by RPA (SOU, 2014). RPA can potentially create benefits for municipalities by executing structured tasks and reducing the need for employees to perform repetitive and monotonous work; in turn, reducing cost and reducing lead times (Lacity and Willcocks, 2016; Madakam et al., 2019). However, although RPA appears to be a promising technology for local government, there is little empirical evidence for such claims. Much of the literature on RPA applications concern private organizations, and it remains to be seen if RPA will bring the same benefits to local government organizations. Furthermore, automation of administrative tasks in this context challenges our understanding of the actors involved in public service provision (Lindgren et al., 2019), calling for further studies on the stakeholders involved.

\subsection{Stakeholder theory as an analytical lens}

Digital government initiatives typically involve a large set of stakeholders (Axelsson et al., 2013). A stakeholder is here understood as "[...] any group or individual who can affect or is affected by the achievement of the organization's objectives" (Freeman, 1984, p. 46). As an entity, a stakeholder can thus refer to individuals, groups, organizations, institutions, societies and even the natural environment (Mitchell et al., 1997). The main contribution of Freeman's original work was a set of managerial principles and tools that can be used to describe firms in terms of their stakeholder relationships (Flak and Rose, 2005). These principles force managers to openly and thoughtfully address questions about the purpose of the organization (or sub-group) and the responsibilities of managers to specific stakeholders (Freeman et al., 2010). These principles have been adapted to the e-government context, acknowledging the technological dimension of e-government (Scholl, 2001; Scholl, 2004). In relation to e-government, technology can be understood in terms of (1) something that entails a number of stakeholders, (2) being a stakeholder, (3) a mediator between stakeholders, (4) a modifier of relationships between stakeholders, and (5) a determinant of, or influencing, stakeholder actions (Flak and Rose, 2005).

The original definition of stakeholders (Freeman, 1984) is general and highlights an important fact; if the scope of the analysis for identifying stakeholders is not limited, just about anybody can be a stakeholder (Tennert and Schroeder, 1999). Several scholars have therefore presented stakeholder types that can be used for discussing stakeholders in e-government projects. For example, Heeks, 2006 has formulated a typology of e-government system stakeholder roles that can be used to label the stakeholders in relation to e-government projects (see tb1). These roles can be divided into two, partly overlapping, stakeholder groups; those involved with the development of the e-government system; and those involved with operation of the e-government system. Note that one stakeholder can take on several roles, and that one role can be taken on by several stakeholders (Heeks, 2006). Since these roles can be overlapping, meaning that the same individual or group can have several of these roles, it is important to identify and analyze these stakeholders in relation to the project at hand. Heeks, 2006 argues that this analysis should be an integral part of the initial phase of an e-government project and suggests that, when analyzing stakeholders, one should examine to what extent the roles are present, if there are overlaps between the roles, and to what extent there is conflict or cooperation between the different stakeholders. In this paper, we use Heeks' (2006) typology as a point of departure for mapping stakeholders in an automation initiative in a large Swedish municipality. 


\section{RESEARCH DESIGN AND CASE STUDY INTRODUCTION}

This paper covers a qualitative and interpretive case study (Walsham, 1995) set in one of the larger municipalities in Sweden (approx. 160000 citizens); here referred to as the Municipality. This work is part of a larger research project that runs over three years, from 2020 to 2022 (Lindgren, 2020). One of the goals of the overarching research project is to map current developments and use of digital technologies for implementing automated case handling in local government. The Municipality (as an organization) is one of the largest employers in the local geographical area, with approx. 9000 employees (plus approx. 1200 employees in municipal companies). Policy implementation and work at the Municipality is organized through seven departments, each led by a committee and a committee director. The different departments span a vast range of public service areas (such as elderly- and childcare; education and labor market; culture and leisure; environment and city planning; social and welfare). Within the organization there is also a city council committee and internal support functions (e.g., HRM, finance, IT).

In order to accelerate the Municipality's digital transformation, a Digitalization Group has been created, including the following roles (plus a head of unit and an administrator);

- Director of Digital Transformation,

- Automation Leader,

- Project Management Office Leader,

- Innovation Leader,

- IT-governance and IT-Architect Leader.

The case study data explored in this paper is centered around a strategic initiative, which the Municipality calls "building automation capacity". The initiative was initiated by the Director of Digital Transformation as an addition to the already existing structures and methods for digital transformation in the organization. The responsibility for leading this particular initiative has been assigned to a newly hired expert in system development and business process analysis, here referred to as the Automation Leader. According to the interviewee inhabiting this role, automation capacity concerns; "... knowledge about what it [automation] means and what benefits it can bring, in order to be able to come up with new ideas on what can be done to solve the problems in the organization. So, it's a matter of competence. I also believe that we need a shared picture of how ideas can be turned into reality, and that's a capacity." (Automation Leader, February, 2020). When asked what actors in the organization that ought to build and inhabit this capacity, the Automation Leader states that "...the Municipality as an organization should have the capacity. And that makes it extremely multifaceted, really... but it's a question of everybody wanting, and having the ability to, and knowing, how we should do it" (Automation Leader, February, 2020). Automation capacity is hence understood as a general knowledge about digitalization and automation, that employees are expected to develop, complemented with structures and methods in the organization that can capture and help realize employees' automation ideas. As part of preparing for and building said capacity, multiple projects have been initiated in the Municipality during the last 1,5 years. These projects include e.g., two pilot projects for RPA implementation, and a project called FormFree2020, aiming to digitize all paper forms in the municipality.

In our data collection, we used the Automation Leader as the hub for data collection and first interviewed a smaller set of stakeholders identified by this person. Through a snowball sampling technique (Patton, 1980), we then identified a larger group of people who were involved in advancing the municipality's digital transformation efforts, including automation of internal administrative tasks. The respondents were spread across six of the seven departments/committees and are predominantly working as managers or business developers. We also identified and interviewed a number of people whose work is affected by the projects initiated to build the Municipality's automation capacity. We conducted 21 interviews with 18 respondents (between February 2020 and January 2021). The Automation Leader was interviewed on three occasions (in February, May and June 2020), and the Manager of the City Contact Center was interviewed twice (in November 2020). The first interview was conducted in-person. Due to the covid-19 pandemic, the subsequent interviews were conducted through video calls, using Zoom or Teams, with a duration of approximately 90 minutes per interview. All interviews were transcribed.

In our analysis of how different stakeholders at the Municipality interpret automation as part of the municipality's ongoing digital transformation, and their respective views on expected outcomes of automation, we treated all interviewees in terms of being stakeholders in relation to the ongoing automation initiative. The interviewees were categorized into different types based on Heeks' (2006) e-government stakeholder roles. We then proceeded to extract and compare views on (a) digitalization, (b) automation, and (c) expected outcomes of automation for the Municipality from the transcripts. In addition, we have actively searched for commonalities and tensions in the stakeholders' views on these phenomena. For the purposes of this paper the analysis was hence mostly deductive (in terms of using stakeholder theory as a theoretical lens; see below), although still allowing for additional themes to emerge from the material.

\section{A STAKEHOLDER ANALYSIS}

Figure 1 (fig1) presents an overview of the interviewees, including which department they belong to and their stakeholder role(s) using the roles in Table 1 as a theoretical lens. As stated previously, the case study centers around the mission of developing "automation capacity" in the organization, guided by the Automation Leader. In short, the Automation Leader's tasks include to inform and inspire key stakeholders in the organization about automation and its potential uses for the Municipality. Having no mandates or budget of his own, he is reliant on other stakeholders in the organization to realize his vision. For this reason, it is of interest to investigate these stakeholders' views on digitalization in general, and automation in particular.

Based on their professional role and relationship to the initiative to develop automation capacity in the municipality, each interviewee has been labeled with one or two stakeholder roles. In our analysis of the stakeholders' views on digitalization and automation, each interviewee was treated as a stakeholder (as an 


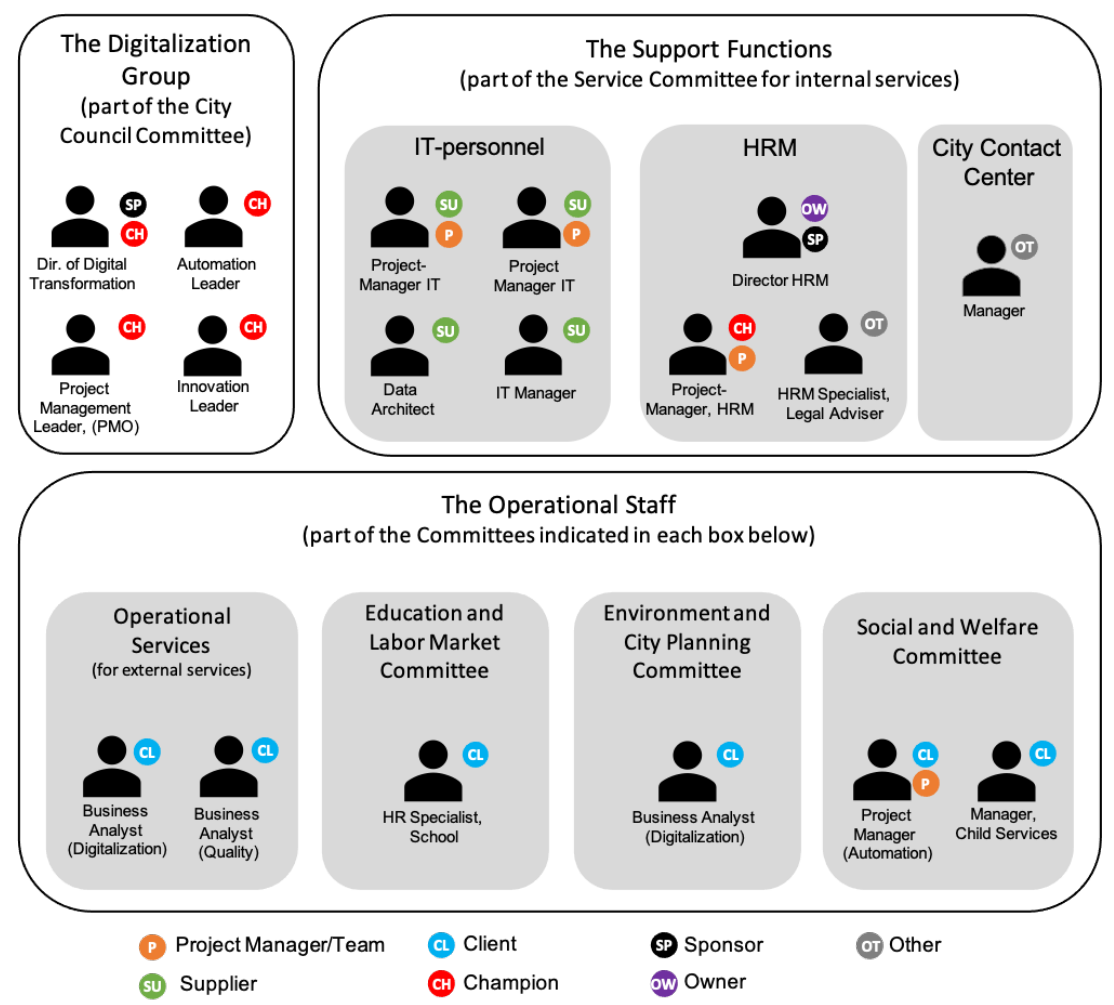

Figure 1: The interviewees, their organizational belonging and stakeholder role(s).

individual). However, based on their organizational belonging in the organization, we have grouped these stakeholders into three overarching groups; (1) The Digitalization Group (The City Council Committee); (2) The Support Functions (three groups within the Service Committee: IT, HRM and City Contact Center); and, (3) The Operational Staff (the Committees providing public services to citizens and others). This grouping aims at mirroring some of the most salient commonalities and tensions found in the interview material. The scope of this map illustrates a large enough sample of stakeholders in the organization for investigating and unveiling important aspects concerning the Municipality's ongoing initiatives to automate administrative work; it is not a complete and exhaustive stakeholder map.

\subsection{The Digitalization Group}

Each department and committee is responsible for their own digitalization of work. In order to promote and help inspire further digitalization, the Digitalization Group was formed. Hence, the Digitalization Group is a new organizational function within the municipality and most of its members have a background in the private sector, with limited, or no, previous experience of working in a public organization. We interviewed four members of this group, all of which can be understood as Champions in the stakeholder typology (Heeks, 2006). As Champions they promote digitalization and automation of work and seek to justify its implementation. The Director of Digital Transformation, who is the leader of this group, is also considered a sponsor (SP), as he is responsible for a smaller budget and holds the mandate to financially support the establishment of automation capacity. This group operates on the strategical level within the municipality and their work mainly consist of strategizing and policymaking.

This group of stakeholders consists of individuals that work closely together and have each been assigned a specific focus area for digitalization (e.g., automation; innovation; project management; IT-governance). Regardless of their area of expertise, they were hired to be advocates of digitalization and it is therefore not surprising that they view digitalization as something that is important and positive for the organization. They all described digitalization as an integral part of organizational development and natural course of action to become a modern and sustainable organization. From the interviews, it is clear that this group of stakeholders see digitalization as both the driving force, and the method, for developing the organization.

Automation, in turn, was described in terms of letting digital technology execute administrative and repetitive tasks, without having to involve people in the process. For these interviewees, automation can be achieved through several technologies; RPA being one of these technologies. The Automation Leader highlights that the core issue is not what technologies to use, but rather how to build an understanding in the organization of the uses and merits of automation (i.e. the automation capacity). Interestingly, although there is a role assigned in the group to guide the development of this understanding, several of the interviewees from the Digitalization Group also mentioned that the preferable solution would be 
to "innovate" in a way that removes tasks altogether, rather than replacing people with software robots. They expressed the expected outcome of automation as improving and strengthening different, if not most, areas of the municipality. As such they echoed political directives and the discourse seen on national and regional levels that push for further digitalization. This group's outlook on what the organization can do with digital technology is hence optimistic, with the Director of Digital Transformation expressing that the transformative power of digitalization "will enable us to give our co-workers new super-powers to do new things" (Director of Digital Transformation, September, 2020).

In their efforts to develop automation capacity in the Municipality, the Digitalization Group is striving to inspire and encourage members of the organization to take an interest and actively pursue digital transformation opportunities for their respective areas. Reoccurring "inspiration lunches" is a central tool for their work, referring to lunchtime lectures that they organize and that anyone in the organization can attend. Their work also includes developing and making available methods and channels of communication that can be used by employees throughout the municipality to realize their digitalization and automation ideas. In addition, the members of the Digitalization Group visit the various departments of the municipality, participating in workplace meetings and internal workshops aiming at digitalization and automation. Their main points of contact at the departments are managers, strategists, and business developers at the various departments and committees of the municipality.

\subsection{The Support Functions}

We have interviewed employees working in departments belonging to the Service Committee, i.e., the sub-organizations within the municipality that are responsible for internal services (e.g. HR, IT). These interviewees represent three important stakeholder groups that are key for understanding the Municipality's ongoing digitalization and automation; (1) IT personnel; (2) Human Resource Management (HRM); (3) the centralized City Contact Center.

4.2.1 IT personnel. We interviewed four employees at the $\mathrm{Mu}-$ nicipality's IT-department, with various roles and responsibilities. Using Heeks' stakeholder typology, all of these interviewees can be understood as Suppliers (SU) of the technology and related resources required to build automation capacity in the Municipality. Two of these also function as Project Managers (P) responsible for RPA pilot projects in which they analyzed, designed, and built a RPA solution together with representatives of the HRM group and an external RPA provider.

Looking at this stakeholder group, they are all experts in digital technology. They mainly described digitalization as denoting that something (typically information) is digital, in contrast to being accessible on paper. However, they also view digitalization as being closely connected to business development, with businesses processes being supported by digital solutions or functions. One of the interviewees pointed to the conceptual confusion surrounding digitalization and digitization (in Swedish, the term digitalization is often used to mean both digitalization and digitization), saying that it sometimes causes communication difficulties. Automation, in turn, is viewed as digital technologies used to increase efficiency by reducing steps in workflows. This can involve an IT system, systems integration by various methods, or business intelligence reports. Their definition of automation is hence broad and inclusive. These interviewees emphasized that automation is nothing new, it has existed for decades. However, the term automation has become a buzzword in the organization that is predominantly used by actors not working with IT. Interestingly, the IT personnel did not view RPA as a good solution for automation, but rather as an alternative method of connecting systems to each other, in contrast to e.g. system integration or utilizing API. In addition, they were also critical of RPA, viewing it as a last resort solution: "There are some use cases where I don't really see any other alternative, and in those cases, it is an exceptionally good solution. It is good that the alternative exists, but often there are, in my opinion, better solutions, and in those cases I think those should be used." (Data Architect, December, 2020). In addition, their experience with RPA so far had furthered their hesitance towards it, reporting that RPA is expensive, problematic and sensitive to slightest change, therefore preferring other solutions if possible.

The explicit efforts to advance digitalization and automation in the municipality was viewed as a possibility to help eliminate simple and repetitive tasks. This corresponds well with their main purpose of supporting the organization. They operate as a support function, meaning that they rely on the established structures and rules of procedure established in the organization. They provide day-today technical support to employees as part of their mission. In contrast, developmental work has to be requested and sanctioned by managers in the committees. This means that an individual employee cannot contact the IT department directly in order to realize an automation idea. Related to this, the IT department is set with the task to maintain and streamline the digital infrastructure in the Municipality. As part of this task, the IT personnel has lobbied for other parts of the organization to discuss digitalization and automation in terms of organizational requirements, rather than discussing specific digital solutions, as the IT department wants to decide on digital solutions that fit the needs of the organization and the existing digital infrastructure. The interviewees reported that representatives from the departments sometimes contact the IT department requesting specific digital solutions (e.g., RPA) without being knowledgeable enough about the nature of this technology; solutions that the IT department has deemed inappropriate for the intended tasks and existing digital infrastructure. The IT personnel are hence set with a difficult task of supplying digital solutions on request by the departments, while also encouraging streamlining and effective use of technology across the departments.

4.2.2 Human Resource Management. We interviewed three employees working with human resource management (HRM) in the Municipality. The HRM function has been involved in recent digitalization and automation efforts, for several reasons. Many HRM processes involve repetitive tasks that are time consuming and oftentimes paperbound; as such, the HRM function was identified by the City Council Committee as a good place to start automating administrative tasks. During the last 1,5 years (2019-2020), two RPA pilots involving HRM were conducted. These pilots were sanctioned and sponsored by the Director HR, who is both Sponsor (S) and the receiving Owner (OW) of the systems created through the 
pilots (Heeks, 2006). The pilot projects involved a project manager (P) from the HR organization. This person is also considered as a champion (C) for building automation capacity in the municipality, being a strong advocate for automation in general. As HR processes rely on a strict legal framework, an additional person from the HRM department was part of the pilot projects; a HR specialist that function as a legal adviser. This person has no clear stakeholder role in relation to the Municipality's initiative to build automation capacity; we hence labeled this interviewee as belonging to the Other (OT) category of stakeholders. Together, the Director HR, the Project Manager, and the HR Specialist, form the HRM stakeholder group.

The HRM stakeholder group described digitalization as an umbrella term, meaning several different things, including both digitization and automation. They were positive towards digitalization and described it as a means to improve work conditions and quality of work, and increase efficiency. By building systems that makes it easy to avoid mistakes, and in some cases even remove the need for human input altogether, digitalization can offload responsibilities from the individual employee. Automation, in turn, was described as a subset of digitalization that is more explicitly focused on processes being executed without the need of human involvement. Automation was also seen as something that can bring unique properties to certain processes that a human cannot, mainly because humans can be biased or otherwise affected in their judgement. If a robot takes care of the process instead of a human, bias can be avoided. This was expressed as a way to increase the legal certainty and fairness of processes.

This stakeholder group is not concerned with specific automation technologies (e.g., RPA, which some of these interviewees have barely heard of); they view the technology as something that concerns the IT department. However, they are particular about digitalization and automation not becoming goals in themselves; the needs of the employees should be the highest priority. They described automation as one of the puzzle pieces in the organization's continuous development, and even mention that it is perhaps one of the smallest pieces, albeit important. Automation is a possible solution only if it is implemented as a response to an identified need of automation in the organization.

4.2.3 The City Contact Center. In contrast to the more established IT and HRM functions, the Contact Center is a newly established function (under the Service Committee), created in response to the municipality scoring low in national comparisons of availability and service satisfaction. The contact center aims to be a single point of contact for all citizen matters. We have interviewed the Manager for this center, whom we consider as an Other (OT) type of stakeholder in our analysis. This stakeholder has a background in the private sector, having worked for a large corporation with a specific emphasis on digital workflows and customer satisfaction. Digitalization was described as including both digital information and digitalized workflows. Digitalization can be used for rethinking, redesigning and reworking a task in order to increase efficiency, increase availability, and save money, e.g., by using digital technologies for pre-filling of forms, avoiding to enter the same information multiple times. Automation, in turn, was described as being a way of eliminating repetitive tasks using RPA or chatbots. In the Manager's view, automation is something that brings great potential for the Municipality to improve current work practices.

The contact center works in a data-driven way, meaning that all incoming errands are documented and analyzed concerning e.g., type, respond time, channel (telephone, e-mail, chat, in-person). Based on citizen contacts and discussions with employees in the departments, the most frequent questions and answers have been documented in a FAQ-system used by the employees in the contact center. As a complement to telephone calls, they have introduced a chat function on the municipality's webpage. The person answering questions via the chat can interact with multiple citizens simultaneously, reducing the personnel required to service citizens.

The use and continuous development of the FAQ could serve as a base for future automation and at the time of the interviews, the Manager had just initiated a project for developing a chatbot that can answer the most frequently asked questions without human involvement. The Manager further described that the contact center had capacity to help the departments with additional tasks; however, much of the digital infrastructure needed for system integration and data sharing between the contact center and the departments is currently lacking. Lack of central coordination and governance has left the departments fully responsible of their own IT, making cooperation across the departments difficult. For the contact center, trying to serve all departments, the great diversity in digital solutions across the departments is particularly salient and challenging.

\subsection{The Operational Staff}

The last group of stakeholders belong to the operational parts of the Municipality, here labeled as Clients (C) when using the stakeholder typology (Heeks, 2006). These are employees working with public services to citizens and hence represent the departments that harbor the majority of processes subject to digitalization and automation efforts. One of the interviewees, the Project Manager Automation, is labeled also as a project manager $(\mathrm{P})$, as this person is responsible for business development (with an explicit focus on automation) within the Social and Welfare Committee. The interviewees covered in this section thus share a close contact with the citizens, but their respective missions are also very different; this group must therefore be understood as a heterogeneous stakeholder group.

The interviewees included in this group described digitalization as including more or less everything involving a computer, e.g., digital information (as opposed to information on paper), e-services and the use of various enterprise systems. Concerning automation, only some of these interviewees had a formed opinion on what automation means and could entail for their work. Those interviewees who were acquainted with automation and had considered it in relation to their work, described automation as being synonymous with RPA technology. It was further described as a way to increase efficiency in administrative processes and to free up time for pursuing other tasks. Others in this group had not considered automation, but had heard the term being used by others in the organization, without seeing opportunities for automation in their own work. Those interviewees with closer interactions with citizens (e.g., the Manager, Child Services) emphasized that only administration can 
be automated, which limits their interest in automation, as much of their work is based on face-to-face interactions with citizens.

All interviewees in this group described the Municipality as an organization that tries to "push" their digitalization forward on multiple fronts and express that the sheer number of digitalization initiatives initiated by the Digitalization Group and other instances in the Municipality is a source of fatigue for many employees. At the same time, they also expressed that they experience persisting problems with current IT-systems and that there is great potential to improve current administrative tasks by "fixing" malfunctioning ITsystems in use. All interviewees in this group are hence in favor of digitalization per se, when it can be used to support their work and make the work day easier. However, they describe a divide between the digitalization initiatives initiated by the Digitalization Group (and other strategists and senior managers) and their own perceived need for digitalization; where the centrally initiated projects tend to treat digitalization as a goal in itself, without explicit concern of the needs of the organization. For the employees working in these departments, the general interest for and competence regarding digitalization was described as being lower (when compared to previous groups), and they testified that they are insufficiently supported by the organization to build the necessary competence needed to understand and interact with the systems in use. One of the interviewees described that employees working with social services and education typically see the interaction between themselves (in their professional role) and their clients as the core task; an exaggerated focus on digitalization and automation is sometimes experienced as conflicting with this focus: "I almost feel that we focus too much on achieving digitalization, when I think about my [business developer] purpose, it concerns improving our work, work smarter, have better meetings and create more value for our citizens, and it should be easier for our co-workers to do so. So, I can sometimes feel that digitalization becomes an aim in itself." (Business Analyst Quality, September, 2020).

One of the stakeholders in this group, the Business Analyst working with digitalization at the Environment and City Planning Committee, stand out in the material. This interviewee was, in contrast to the others in this group, more positively inclined towards automation, seeing it as an opportunity to gain more pleasant working conditions, increased efficiency, better availability, and improved citizen satisfaction. However, this interviewee represent a part of the Municipality that mainly concerns technical services that build less on face-to-face interactions, and that is already highly digitalized. For example, this department includes the Building Permit Office, which services typically centers around the administration of documents. They use e-services as the main communication channel for interacting with citizens and is already using a software robot (similar to RPA) for handling information in submitted documents.

\section{DISCUSSION}

By applying stakeholder theory as a theoretical lens (Flak and Rose, 2005), and using the stakeholder types by (Heeks, 2006), we have explored how different stakeholders in a Swedish municipality interpret automation as part of digital transformation, and their views on expected outcomes of automation in this particular setting. As stated previously, automation of tasks is a good example of a nontrivial organizational change that involve different stakeholders in different ways (cf. Axelsson et al., 2013); one set of stakeholders is stimulating the change (the Digitalization Group), a second set is implementing the change (the Support Functions), and a third set being the receivers and users of the result (the Operational Staff). These groups have different competences regarding digital technology, have very different roles within the Municipality, and hence work toward different goals and values. It is therefore not surprising that our analysis shows that these different stakeholder groups hold different interpretations and definitions of what digitalization and automation means for them, and what outcomes can be expected of accelerating the Municipality's digital transformation.

The Digitalization Group, being champions of digital transformation both ideologically and as part of their function in the Municipality, view digital transformation as the driving force for developing the organization, as well as the method for doing so, exemplifying techno-optimism (Hood and Dixon, 2015). This means that they advocate digital transformation and automation as being inherently desirable, also echoing national policy documents, albeit being aware that digital solutions only are successful if they support municipal operations. Other stakeholder groups are less optimistic, seeing the general drive for digital transformation as sometimes conflicting with the purposes of their professional roles. They are instead more concerned with their own day-to-day-activities, interacting with citizens in their professional roles. Additionally, they fail to see the future and expected value in pursuing more advanced IT solutions when their current IT-systems are difficult to use. In contrast, those working with services that are more technical or document-based, appear to be more positively inclined towards automation. These patterns mirror previous studies on e.g., gender structures in public organizations' IT-projects (e.g., Mörtberg and Elovaara, 2010).

The interviews illustrate that automation of administrative tasks can be achieved with a variety of digital technologies; robotic process automation (RPA) is identified as only one of these technologies. Concerning RPA, some of the interviewees see great potential in this technology, whereas representatives from the IT-personnel see RPA as the last resort for achieving system integration. Although RPA plays a marginal role in the accounts presented in this paper, it is clear in our case study material that SALAR's explicit mentioning of RPA as a suitable solution for automation of administrative tasks has shaped the Municipality's work on automation. The interviewees state that it is important that the IT-personnel, being experts and responsible for the maintenance of IT, is given the final word in deciding on specific digital solutions. However, in the national policy documents encouraging automation, policy makers have already pointed out the suitable technical solution; RPA. This is problematic, considering that RPA might not be the most suitable technology for achieving automation in local government organizations, as exemplified by the IT-personnel's hesitance towards this technology seen above.

The Municipality's formation of a centralized and strategic group for spurring and coordinating digitalization initiatives is challenging, but also promising. All Swedish municipalities have been expected to further their digitalization for a long time, albeit with slow 
progress. Shifting the responsibilities for encouraging and inspiring employees to see digital solutions to their workplace problems from busy managers in the departments, to a separate group of enthusiastic experts on digitalization and business development on a strategic level, challenges existing structures and the status quo (Lindgren et al., 2019). However, the task of digitalizing and automating is still left to employees in the departments; these are the stakeholders that have deep insights into processes and services. Yet, in order to realize their automation ideas, they also need support and help by stakeholders in the support functions, predominantly the IT-personnel; the stakeholders with the technical know-how and insight into the existing digital infrastructure in the overall organization. So, in order for this setup to work, all of these different stakeholders have to work together. More importantly, they have to want to work together. The dissonance in their views on the meaning and goals of digitalization and automation is therefore a potential obstacle for successful co-operation. If the Operational Staff do not see the value in automation, their incentive to pursue automation is non-existent. And if they see the value and pursue it, effective communication may be difficult to achieve if different stakeholders hold different understanding of the concepts involved (cf. Flak and Rose, 2005). In its extension, automation becomes not a matter of technology, but of harmonization of stakeholder views and bridging existing gaps between different stakeholders.

To summarize, the Municipality consists of several large departments that can be viewed as organizations in their own right, with different responsibilities, competences and cultures, making digitalization a challenging task. In the case studied in this paper, it stands clear that the Municipality has taken the national policy makers' (SALAR) recommendations to heart, by initiating several, parallel, and cross-departmental initiatives that aim to further digital transformation (RPA pilots; digitizing paper forms; creating new e-services). To coordinate this endeavor, the Municipality has created The Digitalization Group, consisting of various experts and spearheaded by a Director of Digital Transformation. As each department and committee within the Municipality is responsible for digitalization within its respective part of the organization, the Digitalization Group is not able to directly interfere with or steer how digital transformation is organized. This leaves the Digitalization Group with the task to inspire and encourage other stakeholders in the organization, make recommendations on how to digitalize and automate tasks, and collaborate with other stakeholders to set up processes and methods that can shape conditions for digitalization in the organization. In an attempt to spur and accelerate the $\mathrm{Mu}$ nicipality's digital transformation, the Digitalization Group has set out to develop "automation capacity" in the organization. However, the nature of said capacity and how to develop it remains somewhat unclear. While automation is given much attention by the Digitalization Group, and the attempt to automate administrative work in the organization looks promising, it is questionable to what extent the initiative to "build automation capacity" is focusing on automation per se. We identify signs of 'automation' being used as a way of reviving the discourse on digitalization in an organization where employees are tired of digitalization initiatives, by addressing digital transformation from a new angle and by using a (for the organization) novel concept.

\section{CONCLUSIONS AND FURTHER RESEARCH}

Local governments in Sweden are under pressure by "soft" governance from policy makers and leading politicians to accelerate digital transformation of administrative tasks, in order to make public service provision more efficient and effective. As part of this digital transformation, local governments are currently investigating and implementing digital technologies that can execute administrative functions automatically that were previously carried out by administrative staff. Our analysis was conducted from a stakeholder perspective, investigating (1) how different stakeholders interpret automation as part of the municipality's ongoing digitalization, and (2) their views on expected outcomes of automation of administrative tasks. The answers to these questions were outlined and discussed in the accounts above, with important insights on how the current drive to automate administrative tasks in local government is interpreted and operationalized differently by different stakeholders in a local government organization. These insights can be used to illustrate some of the challenges the municipalities face in this endeavor and guide future research on this topic. For example, our analysis of the interview material shows that different stakeholder groups hold different definitions of what digitalization and automation means for them, and what outcomes can be expected of accelerating the digital transformation in local government. This conclusion is unsurprising, but still important to highlight considering that co-operation between these stakeholders is key for local governments to succeed in furthering their digital transformation. Dissonance in their views on digitalization and automation can pose obstacles to such co-operation. Further work and research needs to be invested in how the conflicting views and interests concerning automation of administrative tasks can affect the municipalities' digital transformation, and how stakeholder conflicts can be handled in this type of development.

Furthermore, the national policy documents point to specific technical solutions for automation (i.e., RPA). It is however questionable if this technology is the best fit and a generic solution for the local government context and what the municipalities want to achieve. The utility of RPA in public organizations needs to be researched further. As part of such investigations, it would also be fruitful to investigate the influence of RPA vendors' marketing rhetoric on national policies concerning automation. It seems as if RPA is receiving a disproportionate amount of attention, in relation to other technologies that can be used to automate administrative tasks.

Two concluding remarks concern our method for generating case study data and analyzing the material for the purposes of this paper. First, in this particular case study, we did not interview employees that are users of automation technologies (called Operators in the typology by (Heeks, 2006)). The reason for not interviewing operators was that the automation initiatives covered in the case study were still under development during the time of the interviews. As part of our larger research project, we intend to return to this organization and continue our data generation when these systems are in use, in order to include the operators' perspectives on automation. Second, we used the stakeholder typology for e-government project presented by Heeks, 2006 to categorize and group the interviewees into different stakeholder types. We 
found it hard to apply Heeks' stakeholder roles on the business analysts present in our material. The business analysts shared some traits with the Champion role in Heeks' typology, but the fit was not perfect. Furthermore, the automation initiative covered in our case study is not a project per se and include stakeholders working on different levels in different (silo-like) departments. In future work, it would be fruitful to investigate if Heeks' typology can be usefully adapted to this type of digitalization initiative. Last, just as there are multiple interpretations of digitalization and automation in the empirical material, the theoretical relationship between digitalization and automation is not conceptually and analytically clear; there is room for theoretical contributions to this area. As stated previously, automation is not new when seen as a general concept, but for many local government organizations it seems to denote something novel. We would like to call for research that investigates this phenomenon further, linking automation to other related theoretical concepts.

\section{ACKNOWLEDGMENTS}

This research is funded by AFA Insurance.

\section{REFERENCES}

K. Axelsson, U. Melin, \& I. Lindgren 2013. Public e-services for Agency Efficiency and Citizen Benefit - Findings from a Stakeholder Centred Analysis. Government Information Quarterly, 30(1), 10-23.

EU European Commission. 2020. eGovernment Benchmark 2020. eGovernment that works for the people. Background Report. Available at: https://ec.europa.eu/digital-single-market/en/news/egovernment-benchmark2020-egovernment-works-people

L.S. Flak, \& J. Rose 2005. Stakeholder Governance: Adapting Stakeholder Theory to E-Government. Communications of the Association for Information Systems, 16(1), 642-664.

R.E. Freeman 1984. Strategic Management: A Stakeholder Approach. Pitman, Boston.

R.E. Freeman, J.Harrison, A. Wicks, B. Parmar, \& S. De Colle 2010. Stakeholder Theory. The State of the Art. Cambridge UP.

R. Heeks, 2006. Implementing and Managing eGovernment. An international text. London: Sage.

Hood, C. \& Dixon, R. 2015. A Government that Worked Better and Cost Less? Evaluating Three Decades of Reform and Change in UK Central Government. Oxford University Press, Oxford.

Goldkuhl, G., Eriksson, O., Persson, A., \& Röstlinger, A. 2014. Offentliggemensamma digitala resurser: utmaningar i samstyrning och samanvändning inom svensk eförvaltning. Rapport.

M.C. Lacity, and L.P Willcocks. 2016. A New Approach to Automating Services, MIT Sloan Management Review (Fall).

I. Lindgren 2020. Exploring Robotic Process Automation in Local Government. EGOVCeDEM-ePart 2020, 249. Published online by CEUR Workshop Proceedings, ceurws.org.

I. Lindgren, C.Ø Madsen, S. Hofmann \& U. Melin 2019. Close encounters of the digital kind: A research agenda for the digitalization of public services. Government Information Quarterly, 36(3), 427-436.
Lipsky, M. 2010. Street-level bureaucracy, 30th ann. Ed.: dilemmas of the individual in public service. Russell Sage Foundation.

S. Madakam, R.M. Holmukhe and D.K. Jaiswal 2019. "The Future of Digital Workforce: Robotic Process Automation (Rpa)," Journal of Information Systems and Technology Management - Jistem USP (16).

H. Margetts \& C. Hood 2012. Paradoxes of modernization: unintended consequences of public policy reform. Oxford University Press.

R.K. Mitchell, B.R. Agle \& D.J. Wood, 1997. Toward a Theory of Stakeholder Identification and Salience: Defining the Principle of Who and What Really Counts. Academy of Management Review, 22(4), 853-886.

C. Mörtberg \& P. Elovaara 2010. Attaching people and technology: Between E and Government. In. Booth, S. et al. (Eds.) Gender Issues in Learning and Working with Information Technology (pp 83-98). Hershey: Information Science Reference.

R. Parasuraman \& V. Riley 1997. Humans and Automation: Use, Misuse, Disuse, Abuse. Human Factors, 39(2), 230-253.

M.Q. Patton 1980. Qualitative evaluation methods, Sage Publications, Beverly Hills.

E. Penttinen, H. Kasslin \& A. Asatiani 2018. How to Choose between Robotic Process Automation and Back-end System Automation? (2018). ECIS 2018 Proceedings. Research Papers. 66. Available at: https://aisel.aisnet.org/ecis2018_rp/66

A.Ranerup \& H.Z. Henriksen 2019. Value positions viewed through the lens of automated decision-making: The case of social services. Government Information Quarterly, 36(4), 101377.

A.Ranerup \& H.Z. Henriksen 2020. Digital Discretion: Unpacking Human and Technological Agency in Automated Decision Making in Sweden's Social Services. Social Science Computer Review, 1-17.

J. Rose, L.S. Flak \& Ø. Sæbø 2018. Stakeholder theory for the E-government context: Framing a value-oriented normative core. Government Information Quarterly, 35(3), 362-374.

SKR SALAR(a). 2018 . Automatisering av arbete - möjligheter och utmaningar för kommuner, landsting och regioner.

SKR SALAR(b). 2018. Automatiserad ärendehantering - att frigöra tid för värdeskapande arbete.

J. Scholl 2001. Applying stakeholder theory to E-Government. Benefits and Limits. In Schmid, B., Stanoevska-Slabeva, K., and Tschammer, V. (Eds.) Towards the ESociety: E-Commerce, E-Business, and E-Government, pp.735-747. Hingham, MA, USA: Kluwer Academic Publishers.

J. Scholl 2004. Involving salient stakeholders. Beyond the technocratic view on change. Action Research, 2(3), 277-304.

SOU. 2016. 2016: 89, För digitalisering i tiden. Digitaliseringskommissionen.

SOU. 2014. 2014:75, Automatiserade beslut - färre regler ger tydligare reglering. Edelegationen.

L. Tangi, M. Benedetti, L. Gastaldi, G. Noci, \& C. Russo 2021. Mandatory provisioning of digital public services as a feasible service delivery strategy: Evidence from Italian local governments. Government Information Quarterly, 38(1), 101543.

J.R. Tennert \& A.D. \& Schroeder 1999. Stakeholder analysis: a tool for network management. Paper presented at the 60th Annual Meeting of the American Society for Public Administration, Orlando, Florida, April 10-14, 1999.

United Nations. 2020. United Nations e-Government Survey 2020. Digital Government in the Decade of Action for Sustainable Development. ISBN: 978-92-1-123210-3. Report available at: https://publicadministration.un. org/egovkb/Portals/egovkb/Documents/un/2020-Survey/2020\%20UN\%20EGovernment\%20Survey\%20(Full\%20Report).pdf

J. Wajcman 2017. Automation: is it really different this time? The British Journal of Sociology, 68(1), 119-127.

G. Walsham 1995. Interpretive case studies in IS research: nature and method, European Journal of Information Systems, 4(2), 74-81.

L.P. Willcocks \& M.C. Lacity 2016. Service automation - robots and the future of work. SB Publishing.

E. Wihlborg, H. Larsson, K, \& Hedström 2016. The computer says no! - A Case Study on Automated Decision-making in Public Authorities. In proceedings from 49th Hawaii International Conference on Systems Sciences. 